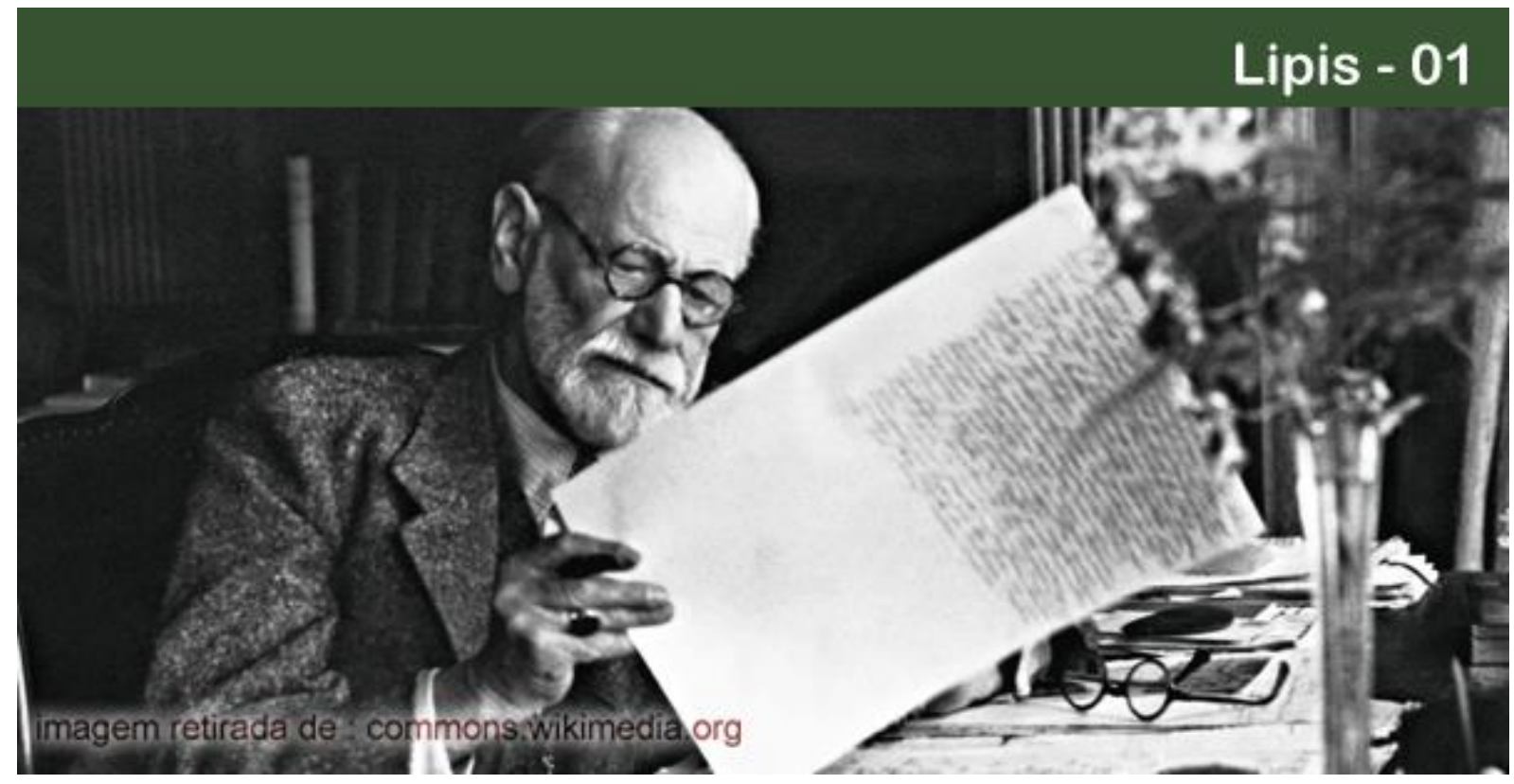

\title{
ENTRE A FANTASIA E A ILUSÃO: O DESAMPARO
}

\section{Gessé Duque Ferreira de Oliveira}

Psicólogo e Psicanalista. Especialista em Gestão em Saúde. Mestre e Doutorando em Psicologia pela Universidade Federal do Pará (UFPA).E-mail: gdfo@live.com.

\section{Paulo Roberto Ceccarelli}

Psicólogo e Psicanalista. Professor da Pontifícia Universidade Católica (PUC-MG), da Universidade Federal do Pará (UFPA) e da Universidade Federal de Minas Gerais (UFMG). Doutor em Psicopatologia Fundamental e Psicanálise - Paris 7/Diderot.Pós-doutor-Paris 7/Diderot.E-mail: paulorcbh@mac.com.

Resumo: Recordando que o conceito de fantasia em Formulações sobre os dois princípios do acontecer psíquico se equipara ao conceito de ilusão, utilizado em $O$ futuro de uma ilusão, procurou-se realizar uma interlocução entre fantasia e desamparo. Primeiramente, é feita uma digressão sobre o conceito de ilusão, tal como trabalhado na obra freudiana, bem como da condição de desamparo, principalmente, psíquico. Além disso, realizou-se um resgate do conceito de fantasia, para enfim estabelecer as possibilidades de interlocução entre desamparo, ilusão e fantasia. Após essa análise, foi percebido que, embora tanto na fantasia quanto na ilusão o teste de realidade não exerce influência, fantasia e ilusão ocupam lugares diferentes na topologia psíquica.

Palavras-chave: Desamparo. Fantasia. Ilusão.

\section{BETWEEN FANTASY AND ILLUSION: HELPLESSNESS}

Abstract: Reminding that the concept of fantasy in Formulations on the two principles of psychic happening matches the concept of illusion, used in The Future of an Illusion, it was sought to make an interlocution between fantasy and helplessness. Firstly, a digression was made about the concept of illusion, as worked in Freud's work, as well as the condition of helplessness, especially psychic. In addition, the concept of fantasy was rescued to finally establish the possibilities of interlocution between helplessness, illusion and fantasy. After this analysis, it was realized that even though the reality test has no influence in both fantasy and illusion, they occupy different places in psychic topology.

Keywords: Helplessness. Fantasy. Illusion.

\section{POLÊM!CA $\mid$ LABORE ( (3)}

Polêmica - Revista Eletrônica da Uerj - Rua São Francisco Xavier, 524, $1^{\circ}$ andar bloco D, sl.1001 • Tels.: +55 21 2334-4088 / 4087 • http://www.e-publicacoes.uerj.br/index.php/polemica/index http://www.labore.uerj.br・ laboreuerj@yahoo.com.br 


\section{Introdução}

Para Freud, o aparelho mental é patológico em sua origem: ele se constituiu como uma defesa contra o excesso pulsional, contra o excesso de paixões (patos = paixões); trata-se de uma organização que se desenvolveu para proteger o ser humano contra os ataques internos (pulsionais, passionais) e externos (mudanças ambientais, perdas diversas), que punham sua vida em perigo. Freud procura responder, e não excluir, conflitos e aspectos obscuros da vida mental. Dessa forma, podemos perceber que a obra freudiana aprecia o silêncio, a sombra, o negativo (PENNA, 1994).

Para Gay (1992), foi na condição de ateu que Freud pôde desenvolver a psicanálise e decretar a futilidade de uma base comum entre fé e descrença, podendo realizar suas descobertas singulares. Freud, acima de tudo, foi subversivo com suas ideias sobre o inconsciente, sobre a etiologia das neuroses e a concepção da sexualidade infantil.

Ao manter e assegurar o conflito, a psicanálise não teria intenção de apresentar uma visão de mundo, ao contrário da religião, por exemplo (FREUD, 1933 [1932]/1996). A questão de saber qual o sentido da vida, a Psicanálise não se proporia responder, muito menos depois de sua virada teórica em Além do princípio do prazer (FREUD, 1920/1996), em que cada pessoa deveria descobrir por si mesma como ser feliz (FREUD, 1930 [1929)/1996]. Já a religião, por sua vez, apresentaria uma resposta, impondo um modelo de vida a ser seguido; uma promessa de vida após a morte, na qual só haveria prazer, sem frustrações (FREUD, 1927/2011).

Três conceitos freudianos instigaram para a construção desse artigo justamente pela sutil proximidade entre eles: ilusão, fantasia e desamparo. Em O futuro de uma ilusão, Freud (1927/2011) define que a força da ilusão está no desejo infantil de proteção. As ilusões surgem como defesa contra o desamparo e se "originam na imaginação, no espaço em que o teste da realidade não tem autoridade" (FREUD, 1927/2011, p. 53). Por outro lado, dezesseis anos antes, em Formulações sobre os dois princípios do acontecer psíquico, Freud (1911/2004, p. 67) define o espaço da fantasia:

Um determinado tipo de atividade do pensar foi apartado do teste de realidade, permaneceu livre deste e ficou submetido apenas ao princípio do prazer. É ele o fantasiar, que já se inicia com o brincar das crianças e mais tarde prossegue com o devanear, deixando então de sustentar-se em objetos reais (FREUD, 1911/2004, p. 67).

\section{POLÊM!CA $\mid$ LABORE}

Polêmica - Revista Eletrônica da Uerj - Rua São Francisco Xavier, 524, $1^{\circ}$ andar bloco D, sl.1001 • Tels.: +55 21 2334-4088 / 4087 • http://www.e-publicacoes.uerj.br/index.php/polemica/index http://www.labore.uerj.br • laboreuerj@yahoo.com.br 
O objetivo deste trabalho é realizar uma aproximação entre fantasia, ilusão e desamparo, conceitos importantes na obra freudiana. Assim como Freud (1927/2011) escreve que com a ilusão seria menos difícil suportar o desamparo, procurou-se, neste artigo, entender a relação que a fantasia estabeleceria com o desamparo. Para tanto, será feita uma digressão teórica nas principais obras de Freud que tratam da fantasia, da ilusão e do desamparo. As principais obras a serem analisadas serão O futuro de uma ilusão (FREUD, 1927/2011) e Formulações sobre os dois princípios do acontecer psíquico (FREUD, 1911/2004). Entretanto, outras obras surgirão como complementares.

\section{Desamparo e ilusão}

Em O Futuro de uma ilusão, Freud (1927/2011) fez uma análise psicológica a respeito do desamparo e da religião, enriquecendo sua obra ao dialogar com um opositor fictício. Nesse ensaio, são abordadas várias questões a respeito da cultura (ou civilização) em contraponto com a religião como ideia ilusória, como algo que ajudaria a suportar o desamparo humano. O que interessa desse texto, principalmente, é a concepção de Freud sobre o desamparo e a necessidade de proteção. Dessa forma, realizaremos alguns resgates a respeito das experiências infantis e adultas de desamparo e a forma de tentar dissimulá-lo.

Para Freud (1927/2011), nosso desamparo, antes de tudo, é o desamparo frente à força da natureza: são ciclones, tsunamis, furacões, tempestades, vulcões que destroem tudo o que construímos com o processo de cultura. A terra se abre, o céu se fecha nos fazendo perceber que somos nada mais que pontos no universo. Além da força da natureza, temos de salientar a relação do desamparo com a desprotegida infância, da qual cremos que nossos pais, heróis e deuses nos protegem.

O sujeito já tem, antes de seu nascimento biológico, seu lugar no discurso do Outro. O sujeito nasce antes de qualquer questão biológica. Muito antes dos filhos virem ao mundo, é comum, e esperado, que os pais planejem como eles serão; já prepararam um lugar para seus filhos na ordem simbólica (PACHECO, 2012). "O Outro é o lugar em que se situa a cadeia do significante que comanda tudo que vai poder presentificar-se do sujeito, é o campo desse vivo onde o sujeito tem de aparecer" (LACAN, 1964/2008, p. 200).

Ao chegar ao mundo em dependência total do Outro, os pais, ou quem acolhe a criança, são os responsáveis pela alimentação, proteção, afeto e outras necessidades infantis (CECCARELLI; LINDENMEYER, 2012). Para o bebê, a falta do Outro traz, sobretudo, a

\section{POLÊM!CA LABORÉ}

Polêmica - Revista Eletrônica da Uerj - Rua São Francisco Xavier, 524, $1^{\circ}$ andar

bloco D, sl.1001 • Tels.: +55 21 2334-4088 / 4087 • http://www.e-publicacoes.uerj.br/index.php/polemica/index

http://www.labore.uerj.br • laboreuerj@yahoo.com.br 
morte ontológica, sendo a função do Outro primordial, inicialmente, "introduzir a criança no mundo da metáfora onde os objetos secundários substituem os primordiais" (CECCARELLI, 2001, p. 96).

A primeira relação da criança com o Outro é de dependência, encarnado inicialmente na mãe. A criança acredita que esse Outro é onipotente, que a protegerá de todos os imprevistos do destino. Pensando que é amada incondicionalmente, a criança faz tudo para não perder essa proteção. Que fique bem claro: ser amada é ser protegida. Essa relação é muito importante para que a criança lide com a sua condição antropológica fundamental de desamparo, no qual o Outro fornecerá à criança os representantes ideativos das pulsões.

Inicialmente, a criança passa por um desamparo orgânico: faz-se necessário que a limpem, alimentem, nutram. Quando surge novamente a fome, a criança cria sua primeira ilusão alucinatória do desejo com os traços da primeira experiência de satisfação, que torna suportável a espera do alimento.

Juntamente com o desamparo orgânico, surge o desamparo psíquico, pois que o bebê não possui um aparelho mental que consiga lidar com as exigências pulsionais. Essa situação exige um novo alimento: amor, carinho, palavras, olhares, afetos, atenção (CECCARELLI, 2012). À medida que as relações vão se estabelecendo com os outros significativos, pressupõese que haja um acolhimento e amparo frente às adversidades da vida.

Em um momento, estamos felizes; no outro, nos acontece uma catástrofe, em outros a natureza nos assola com total crueldade, ou nosso corpo adoece, ou um amor nos faz sofrer. Não há formas seguras de viver, tudo o que criamos são ilusões para enfrentar a dureza, intempestividade e o sofrimento que é a vida. "Não existe uma regra de ouro que se aplique a todos: todo homem tem de descobrir por si mesmo de que modo específico ele pode ser salvo" (FREUD, 1930 [1929]/1996, p. 91).

Para Freud (1927/2011), as ideias religiosas seriam um trabalho de cultura, uma solução para lidar com o desamparo. Essas ideias não teriam vindas ao acaso, mas seriam construídas e perpassadas pela própria cultura. A cultura - e nessa ocasião Freud (1927/2011) não se preocupa em diferenciá-la de civilização -, na concepção freudiana, entende "tudo aquilo em que a vida humana se elevou acima de suas condições animais e se distingue da vida dos bichos" (FREUD, 1927/2011, p. 36). A cultura cerca todo saber humano com o fim de dominar e se proteger das forças da natureza e também abarca todas as instituições capazes de mediar a relação entre os homens.

\section{POLÊM!CA $\mid$ LABORÉ}

Polêmica - Revista Eletrônica da Uerj - Rua São Francisco Xavier, 524, $1^{\circ}$ andar bloco D, sl.1001 • Tels.: +55 21 2334-4088 / 4087 • http://www.e-publicacoes.uerj.br/index.php/polemica/index http://www.labore.uerj.br • laboreuerj@yahoo.com.br 
Para Freud (1927/2011), como já apresentado, a principal forma que a cultura tenta se proteger do desamparo é pela religião: as ideias religiosas proporcionam algum prazer aos homens, promovem a organização social e dão um sentido de proteção às pessoas. Freud (1927/2011) ainda nos assegura que os valores morais dos membros da sociedade não são os únicos fatores a serem analisados numa cultura: ainda há os patrimônios de ideias, criações artísticas, que não passam de ilusões que oferecem satisfações substitutas às renúncias pulsionais, amenizando o desamparo.

Freud (1927/2011) salienta que a criança frente a seus pais, sobretudo ao pai, tinha razão para temê-lo. Contudo, a criança, embora o temesse, se sentia segura e protegida por ele, segura em relação ao desamparo, contra todos os imprevistos da vida. Da mesma forma para lidar com as forças da natureza, quando cresce, o homem as humaniza: transforma as forças da natureza em divindades e lhes veste com um ar paterno do qual teve proteção na infância, seguindo seus modelos infantis.

Segundo Freud (1927/2011), o adolescente ou adulto sempre será uma criança e precisará por toda a vida de uma proteção. Dessa forma, deslocará sua relação com seu pai para os deuses, dos quais tem medo, mas com os quais se sente protegido e amado. "A religião seria a neurose obsessiva universal da humanidade e, tal como a da criança, teria sua origem no complexo de Édipo, na relação com o pai” (FREUD, 1927/2011, p. 109).

\begin{abstract}
A derivação das necessidades religiosas, a partir do desamparo do bebê e do anseio pelo pai que aquela necessidade desperta, parece-me incontrovertível, desde que, em particular, o sentimento não seja simplesmente prolongado a partir dos dias da infância, mas permanentemente sustentado pelo medo do poder superior do Destino. Não consigo pensar em nenhuma necessidade da infância tão intensa quanto a da proteção de um pai (FREUD, 1930 [(1929]/2010 p. 81).
\end{abstract}

Dessa forma, constrói-se uma ilusão destinada a suportar o desamparo humano, uma ilusão com material de lembranças relativas ao desamparo da própria infância. A relação do homem com Deus seria o reflexo da relação da criança com seus pais.

Não é difícil encontrar essas ligações. Elas consistem nas relações entre o desamparo da criança e o desamparo adulto, que é continuação daquele, de modo que, como seria de se esperar, a motivação psicanalítica para a formação da religião se transforma na contribuição infantil à motivação manifesta dessa formação (FREUD, 1921/2011, p. $70)$.

E se realizássemos um paralelo entre os tipos de sofrimento e o desamparo, bem como as formas de suportar o sofrimento e as ilusões?

\title{
POLÊM!CA $\mid$ LABORE
}

Polêmica - Revista Eletrônica da Uerj - Rua São Francisco Xavier, 524, $1^{\circ}$ andar bloco D, sl.1001 • Tels.: +55 21 2334-4088 / 4087 • http://www.e-publicacoes.uerj.br/index.php/polemica/index http://www.labore.uerj.br • laboreuerj@yahoo.com.br 
Enfim, as considerações freudianas nos deixam encurralados: com efeito, somos seres de crença, capazes de acreditar em qualquer coisa. Tudo é bom, desde que o nosso narcisismo seja assegurado, a ilusão da proteção mantida, e o desamparo evitado, por mais que a realidade nos mostre o contrário. Não é a realidade que une os homens, mas os sonhos: vemos o que queremos ver; acreditamos na Providência Divina, nas promessas sociais, na ajuda dos amigos e dos parentes, na loteria... enfim, em tudo que, ilusoriamente, nos conforta, seja o objeto de nossa crença real ou imaginário; visível ou invisível: Credo quia absurdum (CECCARELLI, 2012, p. 102).

Como já ressaltado em Freud (1930/1996), a adicção é uma forma de suportar o desamparo constitucional, e não deve ser entendida apenas a de tóxicos, mas também disfarçada de condutas socialmente aceitas, sendo reveladas por meio da economia psíquica, por uma organização com excesso de pathos.

Para fugir desse estado gerador de angústia, a adicção surge como amortecedor, que possibilita se afastar da realidade e procurar calmaria no mundo interno, procurar uma economia sexual no modo narcísico de satisfação: "A falta de relações objetais tranquilizantes para acolher o recém-nascido em seu desamparo cria 'espaços vazios' que exigem respostas narcísicas imediatas para suportar a intensa angústia aí gerada" (CECCARELLI, 2012, p. 113).

\section{E a fantasia se fez carne}

Pode-se dizer que os espasmos corporais, as paralisias, as cegueiras, entre muitos outros sintomas histéricos, foram fatores que levaram Freud a ter as histéricas como objeto de pesquisa e tratamento. Freud (1906 [1905]/1996), ao escutá-las, com Breuer percebeu que o discurso de suas pacientes se dirigia a reminiscências de vivências sexuais infantis de sedução por um adulto.

Esse fato fez com que Freud relacionasse os sintomas histéricos e obsessivos às experiências sexuais que teriam ocorrido na infância e que haviam sido recalcadas por suas pacientes. O retorno dessas lembranças, na época da puberdade, causaria os sintomas e não as vivências propriamente ditas: "[...] tais traumas sexuais devem ter ocorrido em tenra infância, antes da puberdade, e seu conteúdo deve consistir numa irritação real dos órgãos genitais (por processos semelhantes à copulação)" (FREUD, 1896/1996a, p. 164).

É necessário ressaltar que, nesse período, o que mais nos importa é que Freud (1896/1996b) acreditava que a histérica e o obsessivo haviam vivenciado realmente uma experiência sexual. Essa primeira teoria do trauma ficou conhecida como Teoria da sedução. A ênfase dada a essa teoria fazia do sujeito histérico alguém passivo frente à sexualidade que

\section{POLÊM!CA $\mid$ LABORE.}

Polêmica - Revista Eletrônica da Uerj - Rua São Francisco Xavier, 524, $1^{\circ}$ andar bloco D, sl.1001 • Tels.: +55 21 2334-4088 / 4087 • http://www.e-publicacoes.uerj.br/index.php/polemica/index http://www.labore.uerj.br • laboreuerj@yahoo.com.br 
seria externa a ele; diferente do obsessivo que era ativo. O pai se torna o personagem principal dessa teoria, a mãe aparecerá só mais tarde; ele é o acusado de perversão e histerização de suas filhas - de forma geral a sedução ocorria com as mulheres.

Entretanto, Freud (1896/1996c) passou a não mais acreditar em sua neurótica, apresentando vários motivos, entre os principais, encontramos: 1) o fato de que sua teoria da sedução não teria mais base sólida, pois deveria haver muito mais pais pervertidos que histéricas e 2) o de que no inconsciente não haveria indicações de realidade, de modo que não se conseguiria distinguir entre a verdade e a ficção que é investida com afeto, havendo a possibilidade de os pais serem tema da fantasia sexual. Esse foi um dos primeiros momentos no qual Freud passou a conceber a fantasia.

\footnotetext{
Estes [os sintomas] já não apareciam como derivados diretos das lembranças recalcadas das experiências infantis, havendo antes, entre os sintomas e as impressões infantis, a interposição das fantasias (ficções mnêmicas) do paciente (produzidas, em sua maior parte, durante os anos da puberdade), que, de um lado, tinham-se construído a partir das lembranças infantis e com base nelas, e, de outro, eram diretamente transformadas nos sintomas (FREUD, 1905/1996, p. 261).
}

Essa nova perspetiva levou Freud a rever o mecanismo dos sintomas histéricos. Esses sintomas não seriam derivados das lembranças recalcadas das experiências infantis, existindo a fantasia do sujeito entre os sintomas e as impressões infantis, que havia sido construída a partir das lembranças infantis e eram diretamente convertidas em sintomas.

Freud (1896/1996c) tentava se afastar da justificativa de que a neurose seria causada por fatores constitucionais e hereditários. Mas, no momento em que ele percebeu que sua Teoria da sedução havia sucumbido, ele se viu em uma encruzilhada: se a sedução como fator caiu por terra, os fatores constitucionais e hereditários teriam de voltar. Contudo, ele resolve esse dilema numa torção da “disposição neuropática geral” para a “constituição sexual”. Essa concepção teórica de descartar o trauma sexual infantil e conceber o infantilismo da sexualidade foi de grande importância, porque o sexual na infância é sempre traumático e se é tido como traumático, a própria noção de trauma é excluída (JORGE, 1988).

Em Formulações sobre os dois princípios do acontecer psíquico, Freud (1911/2004) ao contextualizar a passagem do Princípio de prazer ao Princípio de realidade, revela que um tipo de atividade não se deixou dominar pelo Princípio de realidade e ficou submetido apenas ao Princípio do prazer: o fantasiar, que já começara com o brincar das crianças e mais tarde prosseguira para o devanear adulto, destacando ainda que é muito estranho que o teste da

\section{POLÊM!CA $\mid$ LABORÊ}

Polêmica - Revista Eletrônica da Uerj - Rua São Francisco Xavier, 524, $1^{\circ}$ andar

bloco D, sl.1001 • Tels.: +55 21 2334-4088 / 4087 • http://www.e-publicacoes.uerj.br/index.php/polemica/index

http://www.labore.uerj.br • laboreuerj@yahoo.com.br 
realidade não tenha nenhuma influência nos processos inconscientes. "Nos processos inconscientes, a realidade do pensar torna-se equivalente à realidade exterior e o mero desejar já equivale à realização de desejo ou equipara-se até mesmo à ocorrência do evento desejado" (FREUD, 1911/2004, p. 69-70).

Freud percebe que o mundo da fantasia parece estar no quadro entre o mundo interno, que busca a satisfação plena pela ilusão, e o mundo externo, que impõe o princípio da realidade; assim entendemos que nós nos movemos no imaginário, no subjetivo (LAPLANCHE; PONTALIS, 1990).

Essa reviravolta em sua teoria é mencionada em Um estudo autobiográfico, no qual Freud (1924/1996) alega que esse erro poderia ter-lhe consequências fatais para o trabalho. Segundo ele, a maioria de seus pacientes reproduziam cenas de sua infância de serem seduzidos sexualmente por um adulto e, naquele momento, ele acreditara nessas histórias como fatos reais. Contudo se viu na obrigação de reconhecer que essas cenas jamais haviam existido, que eram fantasias de seus pacientes.

Dessa reviravolta em sua teoria, percebera que os sintomas não possuíam ligação com fatos reais, mas com as fantasias: "no tocante à neurose, a realidade psíquica era de maior importância que a realidade material" (FREUD, 1924/1996, p. 40). Dessa forma, "gradualmente aprendemos a entender que, no mundo das neuroses, a realidade psíquica é a realidade decisiva" (FREUD, 1917/1996, p. 370).

As fantasias inconscientes estão na origem dos sintomas histéricos, e as fantasias conscientes seriam os sonhos e devaneios diurnos. No entanto, as conscientes podem se tornar inconscientes ou vice-versa, não sendo irredutíveis a um único registro. Algumas recordações raramente estão ausentes da história da infância neurótica. Freud lhes dá o nome de fantasias originárias ou universais que são as fantasias da cena primária, da castração e sedução: almejam responder ao enigma da origem, respectivamente, do indivíduo, da diferença sexual e da sexualidade, embora a base de todas elas tente resolver o enigma da sexualidade (CABAS, 2005).

A fantasia, segundo Laplanche e Pontalis (2001), é entendida como um:

Roteiro imaginário em que o sujeito está presente, e que representa, de modo mais ou menos deformado pelos processos defensivos, a realização de um desejo e, em última análise, de um desejo inconsciente.

A fantasia apresenta-se sob diversas modalidades: fantasias conscientes ou sonhos diurnos; fantasias inconscientes como as que a psicanálise revela, como estruturas

\section{POLÊM!CA $\mid$ LABORE}

Polêmica - Revista Eletrônica da Uerj - Rua São Francisco Xavier, 524, $1^{\circ}$ andar bloco D, sl.1001 • Tels.: +55 21 2334-4088 / 4087 • http://www.e-publicacoes.uerj.br/index.php/polemica/index http://www.labore.uerj.br • laboreuerj@yahoo.com.br 
subjacentes a um conteúdo manifesto; fantasias originárias (LAPLANCHE; PONTALIS, 2001, p. 169).

Freud, em seu artigo Escritores criativos e devaneios (1908/1996), acredita que os primeiros traços do fantasiar já se encontram na infância. Sendo a atividade predileta da criança o brincar, já poderíamos compará-la a um escritor, pois ela cria um mundo próprio, reajustando os elementos de seu mundo de forma que lhe agrade. O escritor faz o mesmo que a criança: cria um mundo de fantasias, no qual investe bastante, mas conseguindo diferenciá-lo da realidade. As motivações das fantasias são sempre os desejos insatisfeitos, sendo toda fantasia a realização de uma vontade, uma correção da realidade insatisfatória.

\footnotetext{
A fantasia, ou melhor, a fantasmática de um indivíduo seria responsável pelos sonhos, pelos sintomas, pelo agir, pelos comportamentos repetitivos, por todo o dinamismo do indivíduo. Ela modela e estrutura o conjunto da vida do indivíduo (PORCHAT, 2005, p. 25).
}

\section{Fantasia e desamparo}

Depois de apresentarmos um panorama sobre ilusão, desamparo e fantasia, nos perguntamos: poderia a fantasia ser também uma defesa contra o desamparo, conforme a ilusão representa? Para responder a essa questão, faremos algumas elucubrações. Primeiramente, compararemos a noção de Deus em O futuro de uma ilusão (FREUD, 1927/2011) com a ideia de enaltecimento dos pais em Romances familiares (FREUD, 1909 [1908]/1996) depois, as origens da fantasia em Formulações sobre os dois princípios do acontecer psíquico (FREUD, 1911/2004) com a ilusão, também em O futuro de uma ilusão (FREUD, 1927/2011).

Interessante constatar que, em Romances familiares, Freud (1909 [1908]/1996) relata que os pais representam as maiores autoridades para os filhos (como apresentado em $\mathrm{O}$ futuro de uma ilusão (FREUD, 1927/2011), o desejo dos filhos é de se igualarem aos pais, ser grande como eles). Entretanto, com o desenvolvimento, as crianças percebem que seus pais não são seres extraordinários. $\mathrm{O}$ estado de afastamento do neurótico dos seus pais pode ser descrito como "o romance familiar" que não é consciente, bem como a divinização do pai.

Quando a criança percebe que seus pais não são seres onipotentes, a imaginação da criança se volta para libertar-se deles e tenta substitui-los por outros com mais estima. Mas, quando a criança compreende a relação sexual e os papéis nela do pai e da mãe, passa a colocar a mãe em situações infiéis como forma de substituir seu pai por figuras mais importantes (FREUD, 1909 [1908]/1996).

\section{POLÊM!CA $\mid$ LABORÊ}

Polêmica - Revista Eletrônica da Uerj - Rua São Francisco Xavier, 524, $1^{\circ}$ andar bloco D, sl.1001 • Tels.: +55 21 2334-4088 / 4087 • http://www.e-publicacoes.uerj.br/index.php/polemica/index http://www.labore.uerj.br • laboreuerj@yahoo.com.br 
Segundo Freud (FREUD, 1909 [1908]/1996), não podemos ver maldade nessas fantasias. Essas fantasias retornam das recordações originais enaltecidas dos pais. A criança dá as costas à realidade e se volta para o pai da infância, sua fantasia é um lamento pelos dias felizes que tivera, são formas de as crianças enaltecerem os pais e de conservar no inconsciente a onipotência dos pais.

Todo esse esforço para substituir o pai verdadeiro por um que lhe é superior nada mais é do que a expressão da saudade que a criança tem dos dias felizes do passado, quando o pai lhe parecia o mais nobre e o mais forte dos homens, e a mãe a mais linda e amável das mulheres (FREUD, 1909 [1908]/1996, p. 222).

Essa conservação do pai onipotente, nobre e extraordinário no inconsciente não teria ligação com a elevação do pai ao estatuto de Deus? Embora, conscientemente, a criança menospreze e tente colocar seus pais em situações que descaracterizem sua filiação, inconscientemente ela guarda suas primeiras impressões e as transporta para maiores figuras. Acreditamos que poderíamos ver nessa fantasia, também, uma relação com o desamparo.

\section{Conclusões}

Como pudemos perceber em O futuro de uma ilusão, Freud (1927/2011) define que o segredo da ilusão está na força do desejo infantil de necessidade de proteção. Essas ilusões se originam na vida da imaginação, no espaço em que o teste da realidade não tem autoridade. Da mesma forma, percebemos, em Formulações sobre os dois princípios do acontecer psíquico, que Freud (1911/2004) define o espaço da fantasia como um terreno que não é dominado pelo Princípio de realidade, submetido apenas ao Princípio de prazer, ressaltando que no inconsciente, o pensar se iguala à realidade exterior e o desejo, à sua realização: “O âmbito de que se originam tais ilusões é aquele da vida da fantasia; quando ocorreu o desenvolvimento do sentido da realidade, ele foi expressamente poupado do teste da realidade e ficou destinado à satisfação de desejos dificilmente concretizáveis”(FREUD, 1930/2010, p. 37).

A ilusão nada mais é que uma crença motivada pela realização de um desejo infantil como na fantasia. Entretanto a ilusão é calcada num desejo infantil de necessidade de proteção. Já na fantasia, o fator preponderante é a correção de uma realidade insatisfatória (percebemos nela, também, uma forma de satisfação pulsional e, ao mesmo tempo, uma defesa contra o desejo como podemos ver na cena de sedução das histéricas). Embora tanto na fantasia quanto

\section{POLÊM!CA $\mid$ LABORE}

Polêmica - Revista Eletrônica da Uerj - Rua São Francisco Xavier, 524, $1^{\circ}$ andar bloco D, sl.1001 • Tels.: +55 21 2334-4088 / 4087 • http://www.e-publicacoes.uerj.br/index.php/polemica/index http://www.labore.uerj.br • laboreuerj@yahoo.com.br 
na ilusão o teste de realidade não exerça influência, devemos ressaltar que fantasia e ilusão ocupam lugares diferentes na topologia psíquica.

As fantasias se adequam ao contexto da vida, mas manteriam a sua marca. A fantasia oscila em três tempos: alguma situação presente desencadeou o desejo principal do sujeito, desse ponto ele volta a uma experiência passada (infância), na qual esse desejo foi realizado, criando uma situação no futuro que represente a realização. Na fantasia, o "passado, presente e futuro são entrelaçados pelo fio do desejo que os une" (FREUD, 1908/1996, p. 138).

Devemos nos lembrar de que o berço da ilusão é a imaginação, ou seja, a fantasia - lugar em que o teste da realidade não exerce influência, sendo a responsável por enquadrar toda a realidade psíquica do sujeito. Assim, inferimos que a ilusão e a fantasia estão entrelaçadas, já que a ilusão se constrói nas próprias fantasias do sujeito.

Dessa forma, acreditamos que a fantasia também poderia ser entendida como uma defesa ao desamparo, numa tentativa de corrigir a realidade insatisfatória. Diante das dificuldades, o sujeito procura um momento infantil mítico perfeito e cria uma situação no futuro na qual ele possa fantasiar, aplacando sua angústia e lhe gerando um maior conforto psíquico.

\section{Referências}

CABAS, A. G. Curso e discurso na obra de Jacques Lacan. São Paulo: Centauro, 2005.

CECCARELLI, P. R. A sedução do pai. GRIFOS, Belo Horizonte, n. 18, p. 91-97, out. 2001.

CECCARELLI, P. R. Laço social: uma ilusão frente ao desamparo. Reverso, Belo Horizonte, v. 31, n.58, set. 2009, p. 33-41.

CECCARELLI, P. R. A mentira como organizador social. Cronos: R. Pós-Grad. Ci. Soc. UFRN, Natal, v. 13, n. 1, jan./jun. 2012, p. 99-109.

FREUD, S. Observações adicionais sobre as neuropsicoses de defesa (1896). In: Obras completas de Sigmund Freud: edição standart brasileira. Trad. de Jayme Salomão. Rio de Janeiro: Imago, 1996a. V. III.

FREUD, S. A etiologia da histeria (1896). In: Obras completas de Sigmund Freud: edição standart brasileira. Trad. de Jayme Salomão. Rio de Janeiro: Imago, 1996b. V. III.

FREUD, S. Extratos dos documentos dirigidos a Fliess. Carta 69, 21 de setembro de 1897 (1896). In: Obras completas de Sigmund Freud: edição standart brasileira. Trad. de Jayme Salomão. Rio de Janeiro: Imago, 1996c. V. I.

FREUD, S. Minhas teses sobre o papel da sexualidade na etiologia das neuroses [1906 (1905)]. In: Obras completas de Sigmund Freud: edição standart brasileira. Trad. de Jayme Salomão. Rio de Janeiro: Imago, 1996. V. VII.

\section{POLÊM!CA $\mid$ LABORE}

Polêmica - Revista Eletrônica da Uerj - Rua São Francisco Xavier, 524, $1^{\circ}$ andar bloco D, sl.1001 • Tels.: +55 21 2334-4088 / 4087 • http://www.e-publicacoes.uerj.br/index.php/polemica/index http://www.labore.uerj.br • laboreuerj@yahoo.com.br 
FREUD, S. Escritores criativos e devaneios (1908). In: Obras completas de Sigmund Freud: edição standart brasileira. Trad. de Jayme Salomão. Rio de Janeiro: Imago, 1996. V. IX.

FREUD, S. Romances familiares (1909[1908]). In: Obras completas de Sigmund Freud: edição standart brasileira. Trad. de Jayme Salomão. Rio de Janeiro: Imago, 1996. V. IX.

FREUD, S. Formulações sobre os dois princípios do acontecer psíquico (1911). In: Escritos sobre a Psicologia do Inconsciente. Rio de Janeiro: Imago, 2004. V. I.

FREUD, S. Conferências introdutórias sobre Psicanálise. Os caminhos da formação dos sintomas - Conferência XXIII (1917). In: Obras completas de Sigmund Freud: edição standart brasileira. Trad. de Jayme Salomão. Rio de Janeiro: Imago, 1996. V. XVI.

FREUD, S. Além do princípio do prazer (1920). In: Escritos sobre a Psicologia do Inconsciente. Rio de Janeiro: Imago, 2004. V. II.

FREUD, S. O futuro de uma ilusão (1927). Porto Alegre, RS: L\&PM, 2011.

FREUD, S. Um estudo autobiográfico (1924). In: Obras completas de Sigmund Freud: edição standart brasileira. Trad. de Jayme Salomão. Rio de Janeiro: Imago, 1996. V. XX.

FREUD, S. O mal-estar na civilização [1930(1929)]. In: Obras completas de Sigmund Freud: edição standart brasileira. Trad. de Jayme Salomão. Rio de Janeiro: Imago, 1996. V. XXI.

FREUD, S. O mal-estar na civilização (1930). In: O mal-estar na civilização, novas conferências introdutórias à psicanálise e outros textos (1930-1936). Direção-geral da tradução de Paulo César de Souza. São Paulo: Companhia das Letras, 2010. p. 13-122.

FREUD, S. Novas conferências introdutórias sobre Psicanálise. A questão de uma Weltanschauung - Conferência XXXV (1933 [1932]). In Obras completas de Sigmund Freud: edição standart brasileira. Trad. de Jayme Salomão. Rio de Janeiro: Imago, 1996. V. XXII.

GABRIEL, Y. Psicanálise e cultura. In: Freud e a sociedade. Rio de Janeiro: Imago, 1988. p. 184-208.

GAY, P. O último filósofo: "Logos, nosso deus". In: da psicanálise. Rio de Janeiro: Imago, 1992. p. 49-77. Um judeu sem deus: Freud, ateísmo e a construção

JORGE, M. A. C. Sexo e discurso em Freud e Lacan. Rio de Janeiro: Jorge Zahar, 1988.

LACAN, J (1964). O Seminário livro 11: os quatro conceitos fundamentais da psicanálise. Rio de Janeiro: Jorge Zahar, 2008.

LAPLANCHE, J.; PONTALIS, J.-B. Vocabulário da psicanálise. São Paulo: Martins Fontes, 2001.

LAPLANCHE, J.; PONTALIS, J. B. Fantasia originária, fantasias das origens, origens da fantasia. Rio de Janeiro: Zahar, 1990.

LINDENMEYER, C; CECCARELLI, P. R. O pensamento mágico na constituição do psiquismo. Reverso, Belo Horizonte, v. 34, n. 63, p. 45-52, jun. 2012.

PACHECO, A. L. P. Da fantasia de infância ao infantil da fantasia: a direção do tratamento na psicanálise com crianças. São Paulo: Annablume, 2012.

PENNA, A. G. Freud e a Sociologia. In: 1994. p. $9-29$

Freud, as ciências humanas e a filosofia. Rio de Janeiro: Imago,

PORCHAT, P. Freud e o tese de realidade. São Paulo: Casa do psicólogo, FAPESP, 2005.

\section{POLÊM!CA LABORE}

Polêmica - Revista Eletrônica da Uerj - Rua São Francisco Xavier, 524, $1^{\circ}$ andar

bloco D, sl.1001 • Tels.: +55 21 2334-4088 / 4087 • http://www.e-publicacoes.uerj.br/index.php/polemica/index http://www.labore.uerj.br • laboreuerj@yahoo.com.br 
ROCHA, Z. O papel da ilusão na psicanálise Freudiana. Ágora, Rio de Janeiro, v. 15, n. 2, p. 259-271, dez. 2012.

SLAVUTZKY, A. A ilusão tem futuro. In: WONDRACEK, K. H. (Org.). O futuro e a ilusão: um embate com Freud sobre psicanálise e religião. Petrópolis: Vozes, 2003, p. 111-118.

Recebido em: 30/03/2019.

Aceito em: 30/05/2019.

\section{POLÊM!CA LABORE}

Polêmica - Revista Eletrônica da Uerj - Rua São Francisco Xavier, 524, $1^{\circ}$ andar bloco D, sl.1001 • Tels.: +55 21 2334-4088 / 4087 • http://www.e-publicacoes.uerj.br/index.php/polemica/index http://www.labore.uerj.br • laboreuerj@yahoo.com.br 